\title{
More Effective Teaching of Statistics Using the History of Analytics
}

\author{
David J. Fogarty ${ }^{1}$ \\ ${ }^{1}$ University of Phoenix, Phoenix, Arizona, USA; University of Liverpool, Liverpool, Uk; Columbia University, \\ New York, USA; Trident University, California, USA
}

Correspondence: David J. Fogarty. E-mail: dfogarty2@gmail.com

Received: January 17, 2018

Accepted: February 5, 2018

Online Published: February 12, 2018

doi:10.20849/aes.v3i1.308

URL: https://doi.org/10.20849/aes.v3i1.308

\begin{abstract}
There are many methods math and statistics teachers have used to make the teaching of statistics more interesting with the aim of improving student success. One of these methods is to relate the application to something interesting. However, an often overlooked method of making statistics more interesting is to go back into the history of why these techniques were created in the first place. This rich history can often give a more logical orientation to students and increase their learning and overall engagement in the classroom. This paper explores some of the historical aspects of statistics and discusses how including this information in the learning plan can potentially help students attempting to learn the subject.
\end{abstract}

Keywords: statistics, mathematics, history, learning, pedagogy, teaching, instruction

\section{Introduction}

Educational theories are being continually formulated and researched every single day. Educational research is a well-developed field and educators should be aware of the many advancements in research which are in terms of the development of new learning frameworks. Understanding some of these learning frameworks can help instructors improve the learning experience for their students and produce a better scholarly and work environment for the instructor. In this work I will focus on one key question which is what makes an effective statistics and/or quantitative analysis teacher. By pursuing this critical topic we will accomplish the alleviation of anxiety many students face over the need to take statistics courses. It is the experience of this author after having been teaching statistics and quantitative analysis along with courses from other disciplines for over a decade that a large proportion of students have a fear of learning statistics. This is compounded in graduate courses especially where students have had a bad experience with a statistics course they took at the undergraduate level.

Before we delve into improving statistics instruction via the introduction of the history of statistics let's begin by exploring some of the recent research in improving statistics instruction. Prodromou (2015) discussed the use of interactive technological environments which allow students to observe graphical representations of data that support their understanding of statistical concepts. Casleton et al., (2014) demonstrated that by introducing the commonly underemphasized concept of measurement error, students will have a better chance of attaining a better understanding of variability and enthusiasm for the field of statistics. Similarly, Bailey et al., (2013) discussed the benefits of enhanced student learning of non-calculus based introductory statistics via the introduction of discovery-based projects. Ramler and Chapmin (2011) also explored the introduction of statistical research to undergraduate mathematical statistics students using the Guitar Hero video game series. Hiedemann and Jones (2010) found that although in class outcomes were statistically equivalent Academic Service Learning proved to be more effective than Case Studies in promoting students' appreciation of the relevance of statistics for their professional development. Moreover, Pfaff and Weinverg (2009) studied whether hands-on activities increased student understanding of statistics. Lesser and Pearl (2008) explored the use of fun concepts (e.g. movies and cartoons) to improve the student comprehension of statistics. In terms of teaching statistics online Tudor (2006) generated some interesting insights related to success and the instructor's overall involvement in the course. Richardson et al., (2004) did some interesting work with board games, Morse code and the alphabet to teach linear regression analysis. Martin (2003) explored the use of analogies and heuristics in teaching introductory statistical methods. Friedman et al., (2002) explored the use of humor in the introductory statistics course linked to improving the relationship between student and teacher, reducing stress, increasing interest in the course and enhancing recall of the material. Finally, Sowey (1995) researched how to improve the teaching of statistics by making it more memorable. 
There are also some studies which have explored the interesting history of statistics as a way to engage students (Bakker, 2003; Bellhouse, 2005; François and Bracke, 2006; and Ograjensek, 2007). Statistics and data science have an interesting history with excitement and drama which can be told in a similar manner to a historical fiction novel even though in this case the history is real. For example, there are elements related to religion, international, trade, wars, crime, beer, gambling, the industrial revolution, corporate espionage and interesting scientific discoveries such as turning the principles from the evolution of species into computer code.

However, each of these studies lacked the qualitative research results the author uncovered as a result of using the history of statistics in the classroom. Moreover, this study represents the first documented use of the history of statistics in an asynchronous online classroom setting which represents a particular challenge given the difficulty of the subject and the lack of face-to-face interaction between students and the instructor.

In the following paragraphs I am going to introduce some of the more interesting aspects of statistical history that could be introduced into any statistics course. This review is by no means exhaustive and in fact is really just scratching the surface in terms of what is available.

The first interesting historical aspect of statistics is the study of ancient cultures and how it was discovered that they thought about probability theory and that there is evidence of games of chance. Pictures of museum exhibits showing primitive dice instruments made from bones can be very interesting. Furthermore, it can be demonstrated that the study of probability may have been delayed for many years in man's existence after the advent of organized religion but began to show up again in order to gain an advantage in games of chance. Some of the great probabilists who developed probability theories around games of chance included the work of Cardan, Pascal and Fermet. Pascal and Fermet are credited as the founding fathers of probability theory basing their early work on rolls of the dice.

Insurance and life tables are another interesting historical tale which can enhance the teaching of statistics. At one time in our history we never recorded the death of individuals because it was a celestial event and not something that science could ever explain. When society became more organized and governments had the need to tax individuals then they needed to record when people died so they would know not to tax them anymore. These recordings of deaths allowed us to study them for patterns (i.e. positive correlation between death and age) and facilitated the creation of life insurance. Sir Edmond Halley who is perhaps most famous for computing the orbit of the famous comet which also bears his namesake is also credited with creating the first probability tables for life insurance which he did in 1693. This was the early days for collecting data especially on human populations and it is hypothesized that Halley became involved partially to help dispel myths about celestial events occurring in certain years being related to increased deaths or births. In reality, Halley really created a population table rather than an actual life table for which he is often credited. However, the information he organized an analyzed definitely set the stage for the life insurance industry and for actuaries to be able to actually develop these tables. What an interesting piece of history to introduce in a classroom!

I think the history of the Cold War also brings some interesting light to probability theory. Andrey Kolmogorov developed many interesting probability theories some of which made a major contribution to Russia defeating the Germans in WWII and in the subsequent Cold War. It was only after the fall of Communism where his works (in addition to other statistical researchers shielded within the Iron Curtain) were able to be applied to a much broader academic and practitioner community. The Kolmogorov-Smirnoff test is an important nonparametric statistical test taught in many statistics courses.

On the same subject of teaching nonparametric statistics another interesting bit of statistics history is Frank Wilcoxon who worked as a group leader of the insecticide and fungicide laboratory of the American Cyanamid Company in Stamford, Connecticut in 1943. Wilcoxon started out as a chemist but later in his career his interest and expertise in the application of statistics to creating chemical products grew. In 1950 he transferred to the Lederle Laboratories Division of Cyanamid where he developed and led a statistical consulting group which represented one of the first of its kind and is considered a frontrunner for the modern business analytics organization. Wilcoxon was also a scholar practitioner who taught at various institutions including the Department of Statistics at Florida State University in Tallahassee and at the Brooklyn Polytechnic Institute. Wilcoxon's courses were known to be interesting to students in statistics as he was able to blend his strong practitioner experience along with the academics. Wilcoxon's statistical research focused on rapid easy statistical methods. In particular, he was interested in ranking methods resulting in his seminal paper, Wilcoxon (1945), in which he introduced both the signed ranks and rank-sum tests which are regarded as cornerstone nonparametric hypothesis testing procedures. This was published with Wilcoxon under the affiliation of American Cyanamid Company and this research focusing on improving the chemistry related to fungicides, fumigants, and insecticides combined with 
the statistics team Wilcoxon managed within this organization represented a version of competing on analytics where Wilcoxon developed these methods in the environment of business statistics where clean data was not always readily available. As mentioned earlier the Wilcoxon signed rank test is standard nonparametric technique learning for any introductory statistics course and the historical understanding can aid in its instruction.

Another interesting piece of statistical history which can be used to teach the use of graphics to tell a story with the data is that of Florence Nightingale who in addition to being one of the most famous nurses ever on the planet also invented a primitive form of the pie chart in order to convince Crimean War Generals that there were a greater percentage of deaths from infection in the hospitals than those directly from the battlefield. Her purpose was to reallocate resources to the hospitals.

The first interesting historical aspect of statistics is in teaching the concept of correlation which is done in virtually every introductory statistics course. The Pearson R cross-correlation coefficient is defined by Salkind (2007) and Weisstein (2010) as a quantity that gives the quality of a least squares fitting to the original data which is suitable for measuring the quantitative relationship between two variables. The interesting part for students of statistics is that correlation analysis dates back to Karl Pearson who first used the technique in a mission to validate Darwin's Theory of Evolution while he was the editor of the famed academic journal Statistica. Since Pearson many new similar measures have been derived in order to make the calculation more efficient when dealing with different types of data. For example, the technique has evolved over the years to accommodate various types of data such as mixed dichotomous and continuous data and purely dichotomous data. These are often taught as a part of the nonparametric section of an introductory or more advanced statistics course.

When introducing Bayes Theorem to students in an introductory statistics course it would be useful to also discuss the history of the theorem in particular the Presbyterian minister Reverend Thomas Bayes. Bayes was an interesting character who was highly educated and one could speculate was exploring science in relation to religion when he was conducting his research in mathematics. Bayes has only two known named publications one of which was around mathematics and the other was religious. What an interesting combination with Karl Pearson and Darwin's Theory of Evolution and Reverend Bayes developing statistical methods in order to make sense of religion in the face of growing scientific knowledge and discovery?

Fogarty (2017) discussed the history of business analytics starting with the use of analytics to compete more effectively at Guinness Brewery. The creation of the Student's T-test was the result of Guinness hiring quantitative analysts including one particularly brilliant gentleman named William Sealy Gosset. Gossett as explained in Fogarty (2017) was the founder of the Student's T-Test at the turn of the nineteen century. The Student's T-test is introduced in virtually every introductory statistics course. However, very few instructors discuss who Student was and why the name Student? Apparently at the time Guinness Brewery was hiring statisticians and other types of quantitative researchers in order to improve the quality and consistency of their beer and its ingredients. Gosset couldn't publish under his own name as Guinness prohibited this practice in an effort to protect the disclosure of trade secrets. Gossett therefore published his research under the pseudo name "Student" along with Karl Pearson who was mentioned earlier in this article. Interestingly, just about all undergraduates in the US are required to take an introductory statistics class and amazingly many students learning statistics for the first time never learn about the background of this strange name used by the creator of this fundamental statistic. However, the story behind it is a fascinating look at competing with analytics. Even the fact that Guinness forced Gosset to use a pseudo name is evidence that the firm was concerned about the competition getting possession of their trade secrets in the form of intellectual property. As a side note this is a great teaching opportunity for faculty to be able to bring the T-statistic to life especially with a comment on Guinness Brewery which most college students can relate to especially around St. Patrick's Day. Interestingly, Hotelling (1930) wrote that two other analysts from the Guinness Brewery published statistical work under assumed names: Sophister and Mathete. I think it was very progressive for Guinness breweries to have the inclination to disseminate important knowledge and at the same time protect the application of it to their own business process as a trade secret. Many companies today can learn from this this example and attempt to use their developments to make a contribution to knowledge versus keeping everything a trade secret. Guinness continues to get public relations benefits of their efforts over a hundred years later. Knowledge lasts forever as opposed to the more ephemeral brand campaigns we see today. Business statistics students are able to see the true value of business statistics using this approach to addressing the history of statistics.

Another piece of interesting statistical history is the whole quality movement. William Edwards Deming was known as the Father of modern quality. This scholar practitioner from Iowa was key to the recovery of the post WWII Japanese economy and should also be credited for improving the quality of products and services we utilize in the global economy today. Deming looked at quality not only as a statistically based set of tools and principles to 
achieve better quality products but rather took a more strategic approach as to how a firm and its leaders should view quality. This eventually led to one of his great quotes "in God we trust. All others must bring data" In his key paper written in 1953 Deming wrote that better quality through the use of statistical techniques can lead to a competitive advantage for firms. He also pointed out that for a more effective use of these techniques, top management should not only become familiar with the results of statistical methods; they should study also the problems of organization by which to achieve a wider and more effective use of these methods. Interestingly, Deming was first perceived as a good statistician and not a visionary in quality principles. Deming first went to work for the census bureau as they started to introduce sampling methods into the census process. After the 1940 census Deming started teaching Statistical Quality Control to inspectors and engineers. However, after WWII General MacArthur appointed Deming to do a population survey in Japan which would have restored his focus on population statistics. However, given his brief interlude working with US industries after the 1940's US Census and his observations of what was needed in Japanese industry he was able to make the more significant contribution to quality and the strategy of applying statistical thinking into firms (Lewis 2008). I also think the Japanese at the time were much more receptive to these techniques than they would have been at any point in time given they were being led by General MacArthur who was the commander that defeated them in the war. Their US counterparts, however, were starting to ride on the postwar boom in America and had no time to listen to Deming and other quality gurus such as William Juran as their mantra at the time was all about increasing production. With Europe and most of Asia in shambles after WWII they had few serious competitors so there was no major concern over quality. "Why improve if America was the predominant economic power with growing domestic economic growth" they were saying. While Deming's teachings were revered by quality inspectors and engineers they didn't quite convince top managers responsible for the strategy of the firms. These included industries like steel, autos, appliances and electronics. This created a perfect environment for Deming to guide the Japanese as for Japan this was the only way to effectively compete with US companies in items such as cars and consumer electronics. Moreover, the Japanese managers had nothing to lose. This perfect storm environment enabled Deming to go on to become one of the greatest thought leaders in the modern quality movement which would become a colossus of modern management thinking in much of the second half of the $20^{\text {th }}$ century.

Moreover, moving into the $21^{\text {st }}$ century you have a few authors who have commented about how analytics can not only be used to improve firms in terms of revenue generation or cost savings but also be used as the basis for competition. Three key thought leaders who have researched analytic competition include Thomas Davenport (2007), Peter Bell (2013) and Bhaduri \& Fogarty (2016).

Davenport in his famous book "Competing on Analytics" developed the concept that firms have been doing analytics for years but it is only a recent phenomenon that they were actually competing on analytics, that is, using analytics as a basis for competition.

Peter Bell (2013) discussed how the use of analytics is increasingly commonplace in business given the widespread availability of data and high-speed computing. Moreover, he points out that as a result, it's hard for firms to gain a lasting competitive advantage from analytics. However, he goes on to point out that there are companies that have done just that over time. One of these companies is Wal-Mart who keeps its analytics locked away as a trade secret. Another is when companies recognize that sometimes the data they have is more valuable than the actual algorithms themselves and the company works to protect their data. Bell (2013) uses the example of American Airlines and their scheduling algorithms which were made available to other airlines in order to save in airline crew costs. The algorithms were recognized to be fairly straight forward, however, the vast scheduling data that American Airlines had amassed was the real value in this process.

Another way to sustain an analytics advantage discussed by Bell (2015) is for firms to become truly data-driven. By this he means analytics are embedded in the corporate culture from the CEO and down. Examples he cites include Amazon and FEDEX.

Bhaduri and Fogarty (2016) discussed advanced analytics as a way for firms to create a competitive advantage. The Capital One approach is highlighted in which the firm competes on the basis of marginally better models. In Capital One's case this is better credit scores which enable Capital One to select more customers which are identified as subprime by competitors but will prove to be profitable for Capital One. They also utilize customer lifetime value to determine what a customer could be worth and compare with their current performance. Another example is Netflix which competes on the basis of creating better movie preference algorithms so subscribers will continue to watch Netflix shows versus other media outlets. Combining advanced analytics with an alternative and more convenient distribution platform enabled Netflix to severely disrupt their competition to the extent that their original competitors such as Blockbuster video are no longer in business. 
Davenport (2007) admitted that competing on analytics was not entirely new and that some firms such as credit cards and financial services have been using analytics as the basis for competition for many years. What Davenport was referring to makes sense from his examples in the post-industrial world. Davenport created an analytic maturity model known as the Analytic Delta. This model definitely has some components which were similar to those suggested by Deming in the mid-century such as measuring the extent of executive support for analytics. What a great way to link the use of statistics in business during the industrial revolution with the same use of statistics for business in the modern era. What a great way to introduce the statistical approach to operations management in the firm. It can also be directly linked to the modern Lean Six Sigma movement which can then be used as a basis to teach hypothesis testing and even multivariate analysis.

The teaching that correlation does not equal causation is a key principle to learn in an introductory statistics course and this comes with a very interesting historical perspective:

"The invalid assumption that correlation implies cause is probably among the two or three most serious and common errors of human reasoning" is a quote by American evolutionary biologist Stephen Jay Gould (1941 2002).

The quote is found in Gould's book The Mismeasure of Man and is no less than true more than a decade later. However, Gould went too far in some in this aspect and some scientists are now reversing some of his criticisms of earlier work where is given the benefit of the doubt could have advanced important scientific discoveries. For example, in his search for biases in important anthropological work measuring human skulls he created biases himself which are just recently being uncovered.

There is a long history of assuming correlation and causation. The popular media lures the public into this trap everyday with talk of cellphones and brain cancer and depending on which study how coffee is either good for you or bad for you. Some companies even use this to promote their products misguiding consumers and their customers. Breakfast cereal companies promoting the health benefits of fiber or whole-grains is just one example of this where scientific evidence shows whole grains produce just about the same spike in blood sugar levels than processed wheat and in fact the cereal may also contain large amounts of sugar. It also works the opposite way. Sir Ronald Fisher disgraced an otherwise brilliant career by working with tobacco companies to rebuff claims that smoking was linked to health problems stating you cannot imply causation with correlation. The tobacco companies used his fame and reputation to their advantage until the evidence became much too overwhelming and the public just decided for themselves whether or not the product was unhealthy based on the wealth of information from the government and health interest groups such as the American Lung Association. This represents an excellent opportunity to have student look for current examples in the media for assuming correlation and causation all the while using historical accounts like the one reviewed with Sir Ronald Fisher and the big tobacco companies previously.

\section{Analysis}

The use of statistical history has been tested in order to help students become more engages in online classes and on-campus undergraduate and graduate classes in statistics and quantitative analysis offered as a part of a general studies curriculum and also a business analytics curriculum offered as business administrate or MBA program. In the online classes it has been observed that students are more engaged and more likely to post a follow-on response in an asynchronous class discussions. The authors observed in an increase in class participation by up to $10 \%$. Furthermore, the relevance and substantive content of the postings seemed to have increased via the introduction of interesting statistical history into the postings. In the on-campus classes students appeared to be more engaged in the topic and asked more questions related to the topic of both a technical and qualitative nature. From a qualitative perspective the students seem really interested in some of the stories which appears to make them more confident when learning the technical aspects of calculating or interpreting the statistic because they have more context and can relate better to the metric they are attempting to calculate. Students especially like the Guinness example and find it fascinating that a product that they like and consume has a key link to the seemingly unrelated mathematical topic they are learning in class. The same goes for gambling and the development of probability theories. I think all students secretly want to have a system to be able to earn their income from a casino. This was highlighted in the popularity of the movie " 21 " which starred the actor Kevin Spacey and Laurence Fishburne.

\section{Conclusions}

Given the rich statistical history background and the evidence of more engagement and improved learning outcomes it appears that there is a great opportunity to introduce statistical history into the teaching of introductory statistics at both the graduate and undergraduate levels. The history of statistics can be found in numerous books including one recently published by this author (Fogarty, 2017). Another potential source of interesting statistical 
history is interviews with famous statisticians which can be often found in the appendix of peer-reviewed statistical journals like the Journal of Mathematical Statistics. I also find business cases like those with the tobacco companies or cases of unwanted side effects with pharmaceutical product launches can also reap interesting statistical stories. Finally, the literature on quality management especially about the quality gurus is ripe with interesting statistical history. One of the limitations of this study is that the research on the effectiveness of using interesting statistical history to keep students engaged is mainly observational research of students both online and in traditional higher educational settings. Therefore, a suggestion for future research is a quantitative study to gather more evidence supporting the hypothesis that the introduction of interesting statistical history into statistics courses leads to increased student engagement and success.

\section{References}

Bailey, B., Spence, D.J., \& Sinn, R. (2013). Implementation of Discovery Projects in Statistics. Journal of Statistics Education, 21(3), 23-32. https://doi.org/10.1080/10691898.2013.11889682

Bakker, A. (2003). The early history of average values and implications for education. Journal of Statistics Education, 11(1). Retrieved from http://ww2.amstat.org/publications/jse/v11n1/bakker.html

Bell, P. (2013). Creating Competitive Advantage Using Big Data. Ivey Business Journal Online, May/June, 1-6.

Bell, P. (2015). Sustaining an Analytics Advantage. MIT Sloan Management Review, Spring, 1-4.

Bellhouse, D.R. (2005). Probability and statistics ideas in the classroom-lessons from history. Proceedings of the 55th Session of the ISI. Sydney, Australia. Retrieved from https://www.stat.auckland.ac.nz/ iase/publications/13/Bellhouse.pdf

Bhaduri, S., \& Fogarty, D. (2016). Advanced Business Analytics: Essentials for Developing a Competitive Advantage. Springer, Singapore. https://doi.org/10.1007/978-981-10-0727-9

Bhaduri, S., \& Fogarty, D. (2016). Advanced Business Analytics: Essentials for Developing a Competitive Advantage. Springer, Singapore. https://doi.org/10.1007/978-981-10-0727-9

Casleton, E., Beyler, A., Genschel, U., \& Wilson, A. (2014). A Pilot Study Teaching Metrology in an Introductory Statistics Course. Journal of Statistics Education, 22(3), 1-42. https://doi.org/10.1080/10691898.2014.11889710

Davenport, T.H., \& Harris, J.G. (2007). Competing on Analytics: The New Science of Winning. Harvard Business School Press.

Fogarty, D.J. (2017). From Beer to Derivatives: The History of Analytics in Business. Sara Book Publication.

François, K., \& Bracke, N. (2006). Teaching statistics in a critical way: historical, philosophical and political aspects of statistics. Proceedings of ICOTS 7. Salvador, Brazil. Retrieved from http://iase-web.org/documents/papers/icots7/8D2_FRAN.pdf

Friedman, H.H., Friedman, L.W., \& Amoo, T. (2002). Using Humor in the Introductory Statistics Course. Journal of Statistics Education, 10(3), 6-15. https://doi.org/10.1080/10691898.2002.11910681

Heidemann, B., \& Jones, S.M. (2010). Learning Statistics at the Farmers Market? A Comparison of Academic Service Learning and Case Studies in an Introductory Statistics Course. Journal of Statistics Education, 18(3), 26-30. https://doi.org/10.1080/10691898.2010.11889584

Lesser, M., \& Pearl, D.K. (2008). Functional Fun in Teaching Statistics, Research and Recommendations. Journal of Statistics Education, 16(3), 32-38. https://doi.org/10.1080/10691898.2008.11889572

Martin, M. (2003). It's like... you know: The Use of Analogies and Heuristics in Teaching Introductory Statistical Methods. Journal of Statistics Education, 11(2), 33-41. https://doi.org/10.1080/10691898.2003.11910705

Ograjensek, I. (2007). Improving student in-depth understanding of statistics: the case for offering historical insights in statistics courses. Metodoloski Zvezki, 4(2), 219-229. Retrieved from http://www.stat-d.si/mz/mz4.1/ograjensek.pdf

Pfaff, T.J., \& Weinberg, A. (2009). Do Hands-On Activities Increase Student Understanding?-A Case Study. Journal of Statistics Education, 17(3), 34-40. https://doi.org/10.1080/10691898.2009.11889536

Prodromou, T. (2015). Teaching Statistics with Technology. Australian Mathematics Teacher, 71(3), 32-40.

Ramler, I.P., \& Chapman, J.L. (2011). Introducing Statistical Research to Undergraduate Mathematical Statistics Students using the Guitar Hero Video Game Series. Journal of Statistics Education, 19(3), 23-34. https://doi.org/10.1080/10691898.2011.11889623 
Richardson, M., Gabrosek, J., Reischman, D., \& Curtiss, P. (2004). Morse Code, Scrabble, and the Alphabet. Journal of Statistics Education, 12(3), 56-62. https://doi.org/10.1080/10691898.2004.11910628

Sowey, E.R. (1995). Teaching Statistics: Making it Memorable. Journal of Statistics Education, 3(2), 23-27. https://doi.org/10.1080/10691898.1995.11910487

Tudor, G.E. (2006). Teaching Introductory Statistics Online-Satisfying the Students. Journal of Statistics Education, 14(3), 22-26. https://doi.org/10.1080/10691898.2006.11910591

Wilcoxon, F. (1945). Individual Comparisons by Ranking Methods. Biometrics Bulletin, 1(5), 80-83. https://doi.org/10.2307/3001968

\section{Copyrights}

Copyright for this article is retained by the author(s), with first publication rights granted to the journal.

This is an open-access article distributed under the terms and conditions of the Creative Commons Attribution license (http://creativecommons.org/licenses/by/4.0/). 